\title{
High-riding innominate artery: not so uncommon as expected?
}

\author{
Berk Gurpinar $^{1 *}$, Guler Berkiten ${ }^{1}$, Zeynep Aydogdu ${ }^{1}$, and Yavuz Uyar $^{1}$
}

\section{Abstract}

Tracheostomy is both an urgent and an elective surgical procedure that is intended to secure the airway and mostly save the life of the affected patient. In elective cases, adequate preparation of the patient and convenience of the surgery reduces the risk on the account of the patient; on the other hand, emergency cases possess the risk of injury to the vital structures.

We present two cases of aberrantly high-riding innominate arteries that reach the thyroid isthmus. To best of our knowledge, this entity is rarely reported in the literature. We believe that, this situation is more frequent than expected. Our aim is to raise awareness of the risk and alert the surgeons to possible risks

Key words: Brachiocephalic artery, High-riding innominate artery

\section{Introduction}

Thyroid surgery, open or percutaneous dilatational tracheotomy, bronchoscopy, mediastinoscopy and oesophagoscopy are the most common surgeries of the anterior neck. These are potentially safe surgeries because no major vessel is encountered in the surgical field around the trachea. 1

Variations in the branching pattern of the arch of the aorta are well recognized; however, a high-riding innominate artery reaching as far superiorly in the neck as the thyroid gland has only rarely been reported in literature.2-4

We report two cases in which an aberrant innominate artery was rerouted as high as the thyroid isthmus.

\section{Case 1}

59 year-old-male complaining of dysphonia is admitted in 2017 with the diagnosis of squamous cell carcinoma of the anterior glottis. Horizontal glottectomy is planned.

As a routine, bilateral modified apron flaps are elevated and in the anterior neck, strap muscles are identified. Below the thyroid isthmus, a large pulsatile mass (Fig 1) is identified as aberrant innominate artery.

The patient had a large thyroid gland, cricoid cartilage and the first three tracheal rings are palpated and the thyroid gland is delicately elevated superiorly to visualize the tracheal rings.

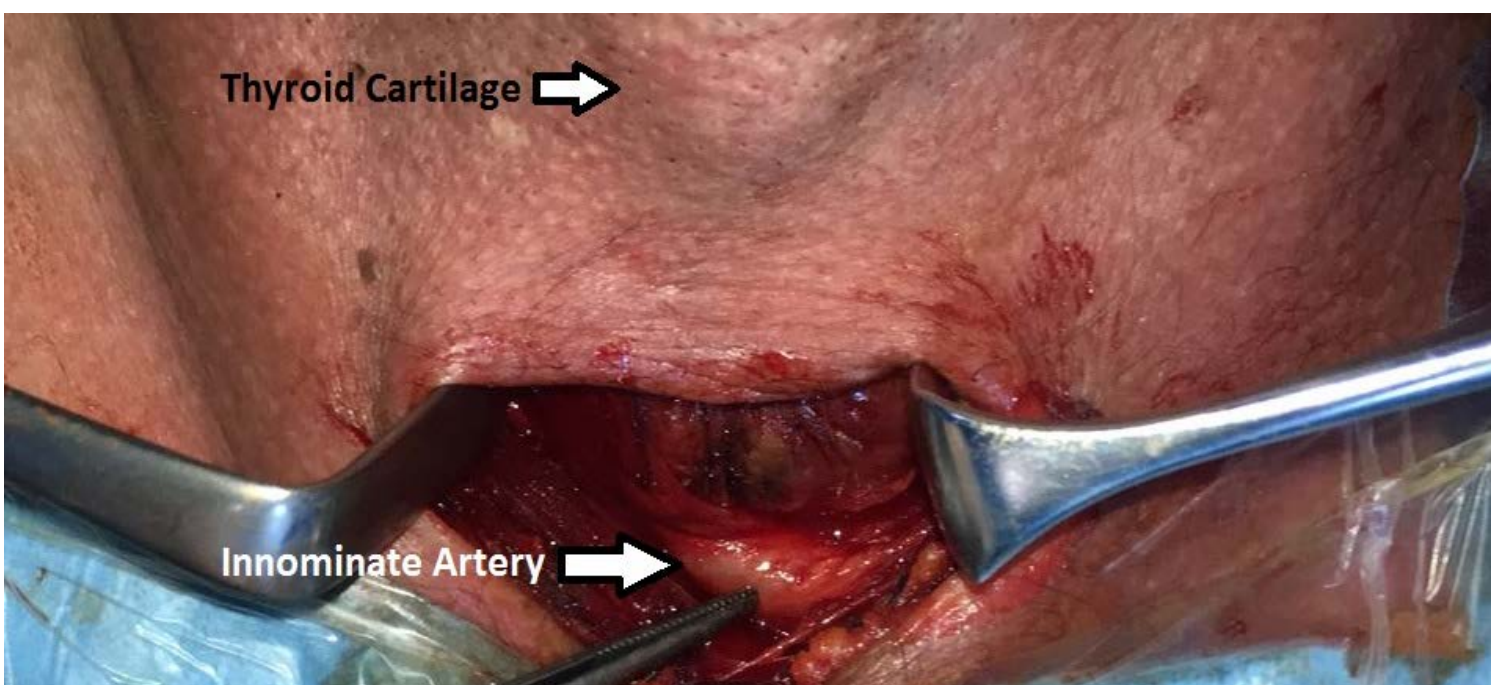

Figure 1. Below the thyroid isthmus, a large pulsatile mass is identified as aberrant innominate artery. Arrows indicate the thyroid cartilage and aberrant innominate artery.

Received 19-08-2017 Accepted 21-08-2017 Available Online 30-08-2017

1 Department of Otolaryngology, Okmeydani Training and Research Hospital, Istanbul, TR

* Corresponding Author: Berk Gurpinar E-mail: b_gurpinar@yahoo.com Phone: +90 5325428212 


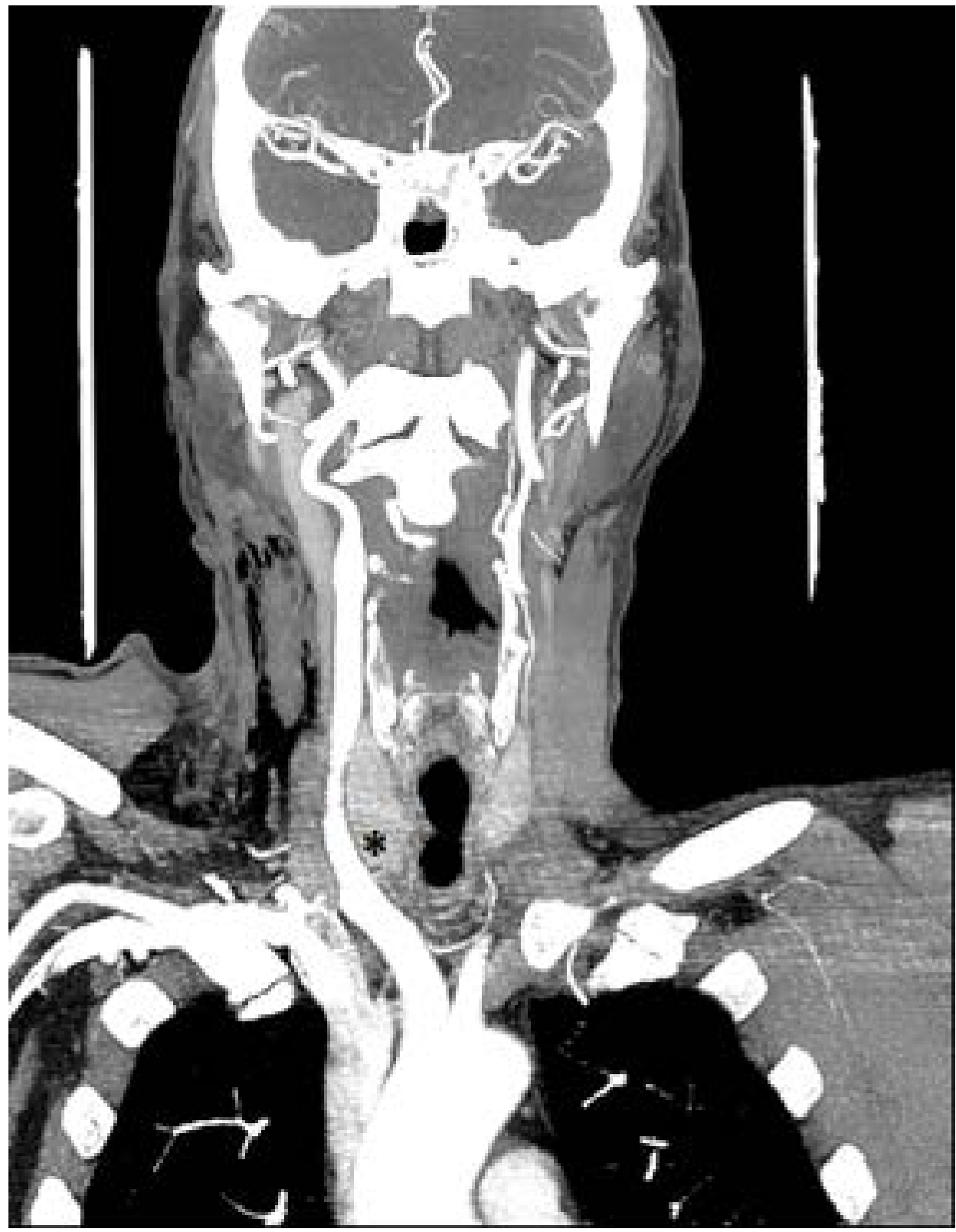

Figure 2. Angiogram shows the high-riding innominate artery $\left({ }^{*}\right)$

Tracheostomy is opened between the second and the third tracheal rings paying attention not to touch the aberrant innominate artery. After the surgery, the angiography supported the diagnosis of the highriding innominate artery (Figure 2).

\section{Case 2}

The 40 year-old-male is admitted in 2016 with the diagnosis of mandibular fracture. Before the surgical intervention, a tracheostomy is planned to secure the airway. A horizontal incision approximately $3 \mathrm{~cm}$ above the sternal notch is made and the strap muscles and the thyroid gland are identified. As in the first case, just below the thyroid gland a pulsating mass is identified as the innominate artery.
The thyroid gland is gently elevated again to visualize the second and the third tracheal rings and the tracheostomy is opened. The angiography supported the high-riding innominate artery.

\section{Discussion}

The innominate (brachiocephalic) artery is the first and the largest branch of the arch of the aorta. It is derived from the aortic sac and the proximal right fourth aortic arch embryological. It normally crosses and passes to the right of the trachea at the level of the ninth cartilage ring, continues upwards and divides behind the sternoclavicular joint into the right subclavian artery and the right common carotid artery.5 
Developmental abnormalities of the aortic arch and variations in the branches and their course are well recognized.1 However, high-riding innominate artery to the thyroid gland is not common and is very unusual.2-4 A high-riding innominate artery is extremely prone to injury during anterior cervical operations such as tracheostomy and thyroidectomy unless unusual course is kept in mind. We believe, finger palpation is very important during the surgery, otherwise subtle pulsations that may not be detected visually could lead to potential complications.

Another paramount is the emergency operations and emergency tracheostomy. Almost always the goal is to establish the airway as fast as possible, that unfortunately creates more risk. To prevent, aberrant courses and variations should always be kept in mind and be emphasized during resident training.

Our aim is to point out that unusual course to the head and neck surgeons in order not to come across that aberrant artery incidentally. In conclusion, an awareness and accurate detection of aberrations in vascular anatomy can be of immense value in alerting the referring clinician to take necessary steps to prevent inadvertent vascular injury, consequent precipitous haemorrhage, and potential death.

Conflict of Interest: The authors declare no potential conflicts of interest with respect to the research, authorship, and/or publication of this article.

Author's Contributions: BG, GB, ZA, YU: Collecting of patients data, Patient examination and operation, writing and revision of article,
Ethical issues: All Authors declare that Originality of research/article etc... and ethical approval of research, and responsibilities of research against local ethics commission are under the Authors responsibilities. The study was conducted due to defined rules by the Local Ethics Commission guidelines and audits.

\section{References}

1. Netzer A, Ostrovsky D, Bar R, Westerman ST, Golz A. Protection of highriding aberrant innominate artery during open tracheotomy. J Laryngol Otol. 2010;124:892-895.

2. Ozlugedik S, Ozcan M, Unal A, Yalcin F, Tezer MS. Surgical importance of highly located innominate artery in neck surgery. Am J Otolaryngol. 2005;26:330-332.

3. Upadhyaya PK, Bertellotti R, Laeeq A, Sugimoto J. Beware of the aberrant innominate artery. Ann Thorac Surg. 2008;85:653-654

4. Racic G, Matulic J, Roje Z, et al. Abnormally high bifurcation of the brachiocephalic trunk as a potential operative hazard: case report. Otolaryngol Head Neck Surg. 2005;133:811-813.

5. Moore KL. The cardiovascular system. In: Moore KL, Persaud TVN, eds. The developing human: clinically oriented embryology. 8th ed. Philadelphia, Saunders; 2008: 285-337. 